\title{
A descriptive analysis of midwifery education, regulation and association in 73 countries: the baseline for a post-2015 pathway
}

Sofia Castro Lopes ${ }^{1}$, Andrea Nove ${ }^{1 *}$, Petra ten Hoope-Bender ${ }^{2}$, Luc de Bernis ${ }^{3}$, Martha Bokosi ${ }^{4}$, Nester T. Moyo ${ }^{4}$ and Caroline S. E. Homer ${ }^{5}$

\begin{abstract}
Background: Education, regulation and association (ERA) are the supporting pillars of an enabling environment for midwives to provide quality care. This study explores these three pillars in the 73 low- and middle-income countries who participated in the State of the World's Midwifery (SoWMy) 2014 report. It also examines the progress made since the previous report in 2011.

Methods: A self-completion questionnaire collected quantitative and qualitative data on ERA characteristics and organisation in the 73 countries. The countries were grouped according to World Health Organization (WHO) regions. A descriptive analysis was conducted.

Results: In $82 \%$ of the participating countries, the minimum education level requirement to start midwifery training was grade 12 or above. The average length of training was higher for direct-entry programmes at 3.1 years than for post-nursing/healthcare provider programmes at 1.9 years. The median number of supervised births that must be conducted before graduation was 33 (range 0 to 240). Fewer than half of the countries had legislation recognising midwifery as an independent profession. This legislation was particularly lacking in the Western Pacific and South-East Asia regions. In most (90\%) of the participating countries, governments were reported to have a regulatory role, but some reported challenges to the role being performed effectively. Professional associations were widely available to midwives in all regions although not all were exclusive to midwives.

Conclusions: Compared with the 2011 SoWMy report, there is evidence of increasing effort in low- and middle-income countries to improve midwifery education, to strengthen the profession and to follow international ERA standards and guidelines. However, not all elements are being implemented equally; some variability persists between and within regions. The education pillar showed more systematic improvement in the type of programme and length of training. The reinforcement of regulation through the development of legislation for midwifery, a recognised definition and the strengthening of midwives' associations would benefit the development of other ERA elements and the profession generally.
\end{abstract}

Keywords: Midwives, Education, Regulation, Association, Professional development, Sustainable Development Goals

* Correspondence: andrea.nove@icsintegrare.org

${ }^{1}$ ICS Integrare, calle Balmes, 30,3-1, 08007 Barcelona, Spain

Full list of author information is available at the end of the article

(c) 2016 The Author(s). Open Access This article is distributed under the terms of the Creative Commons Attribution 4.0 International License (http://creativecommons.org/licenses/by/4.0/), which permits unrestricted use, distribution, and reproduction in any medium, provided you give appropriate credit to the original author(s) and the source, provide a link to the Creative Commons license, and indicate if changes were made. The Creative Commons Public Domain Dedication waiver (http://creativecommons.org/publicdomain/zero/1.0/) applies to the data made available in this article, unless otherwise stated. 


\section{Background}

Tackling poor outcomes in sexual, reproductive, maternal and newborn health (SRMNH) in the post2015 era requires a new paradigm for health, based on universal access and provision of essential quality services to all women and babies. Universal access demands a well-planned, prepared and enabled midwifery workforce [1-4].

There is increasing recognition of the role of midwives in improving SRMNH outcomes and of the environment enablers that improve the quality of midwifery practice. Recent evidence positions midwives as being pivotal to effective SRMNH services $[3,5]$. Educated, regulated and licensed midwives, under adequate management and supervision, can increase the quality of care and positively impact on maternal and perinatal outcomes [2, 3, 5-7]. Midwives, when enabled to work to their full scope of practice within a functional health system, can operate across the whole continuum of care, as they are able to provide care from the community to referral facilities and from health promotion and education [5] to more complex life-saving interventions. Midwives can therefore increase the chances that women will seek care at the most effective time and level [6]. Additionally, evidence shows that midwives, when integrated within multidisciplinary teams and where adequate referral mechanisms are available, can improve SRMNH outcomes [5].

Several international organisations are involved in the strengthening of the midwifery profession, in particular the International Confederation of Midwives (ICM), the World Health Organization (WHO) and the United Nations Population Fund (UNFPA). With the aim of achieving global goals for SRMNH, ICM has identified three pillars for midwifery practice and development: education, to provide a competent, qualified workforce; regulation, to set the scope of practice, and licensing and re-licensing requirements ensuring that midwives provide high-quality midwifery care; and association, that consists of 'an organised body of persons engaged in a common professional practice, sharing information, career advancement objectives, in-service training, advocacy and other activities' and supports the strengthening of the workforce. ICM guides governments and midwives' associations to develop and support their workforce based on these three pillars, collectively known as 'ERA' [8-13].

The State of the World's Midwifery (SoWMy) 2011 [14] and 2014 [2] reports provided evidence on these pillars and on the policy environment in which midwives need to operate to achieve their potential and improve health outcomes. The reality is that highquality SRMNH care is not always available and/or accessible [3]. The 2014 report showed severe health worker shortages: only $42 \%$ of the world's midwifery, medical and nursing personnel are available to women and newborns in the countries where $92 \%$ of all the world's maternal and newborn deaths and stillbirths occur [2].

If education, regulation and association (ERA) are key components for the development of a midwifery workforce able to provide quality care and respond to existing and future SRMNH challenges, it is important to understand how these components vary around the world. Understanding the variations can assist countries or associations to gauge their progress against global standards and benchmarks and provide opportunities for improvements or changes to be made. This study aims to explore specific aspects of ERA and highlight regional differences. It also takes stock of progress since 2011.

\section{Methods}

In 2014, the second SoWMy report was published. The report was coordinated by UNFPA, WHO and ICM with, as technical partner, ICS Integrare. A steering committee was established, including donors and other partners. The 75 low- and middle-income countries included in the 'Countdown to 2015' [15], an initiative to track progress on maternal and newborn mortality and stillbirth rates in high burden countries, were invited to contribute to the report, and 73 did so (see the Appendix). These included countries from all six regions defined by WHO; however, they cannot be considered to be a representative sample of countries within each of the different regions. Ethical approval was received from the University of Southampton Ethics Committee (reference no 7688) prior to the commencement of data collection.

SoWMy 2014 collected detailed information on the midwifery workforce and the environment in which it operates. This process used two strands: a selfcompletion questionnaire, which collected quantitative and qualitative data about the workforce, its education, regulation, professional associations, policy and planning frameworks, and progress since the previous report from 2011 [14], and, for some, a national workshop involving national stakeholders and experts, to identify barriers and solutions for effective coverage of SRMNH care taking into account the four dimensions of effective coverage (availability, accessibility, acceptability and quality) [16, 17]. In this paper, we focus solely on the data from the selfcompletion questionnaire, which countries could choose to complete in English, French or Spanish.

The complete SoWMy 2014 questionnaire consisted of seven modules: (1) SRMNH workforce, (2) education 
and early career, (3) regulation, (4) professional health associations, (5) policies, (6) health infrastructure and workforce planning models and (7) actions taken in midwifery services since 2011 when the previous report was published. The analysis reported in this paper is taken from responses to selected questions in modules 2, 3, 4 and 7 and looks at ERA in more detail than was possible in the published SoWMy reports.

At country level, UNFPA and WHO nominated a lead technical midwifery/SRMNH worker as a focal point for the data collection. The focal points liaised with the Ministry of Health, midwifery associations, education providers, regulators and other key stakeholders to assist with the completion of the survey [18] and validation of the required data. The questionnaire was filled in and submitted via an online platform. A help desk was provided to assist users during the process. Anonymity was assured for those who preferred not to be acknowledged in the final report.

A descriptive analysis of the quantitative data was conducted using Excel (Microsoft Office) and Stata. Cross-regional analysis was conducted based on the WHO regional classification: Sub-Saharan Africa (hereafter AFRO), Eastern Mediterranean (EMRO), South-East Asia (SEARO), Western Pacific (WPRO), Americas (PAHO) and Europe (EURO).

A total of 54 countries took part in both SoWMy 2011 and SoWMy 2014 (see the Appendix). For these countries, change over time is examined where valid comparison could be made. We also analysed openended questions which asked countries to report their own perceptions of what had changed in relation to ERA since 2011.

\section{Results}

The 73 participating countries represented all six of the WHO regions: 41 (56\%) from AFRO, 9 (12\%) from EMRO, 6 (8\%) from SEARO, 6 (8\%) from WPRO, $6(8 \%)$ from PAHO and 5 (7\%) from EURO. The overall results are strongly influenced by the AFRO region which made up over half of the sample. As noted earlier, the regional results cannot be considered to be representative of the region as a whole-just of the Countdown countries within that region.

\section{Education}

In 60 countries $(82 \%)$, the minimum requirement to start midwifery training was reported to be grade 12 or above. This proportion was highest in the AFRO region (95\%) and lowest in the EMRO and EURO regions (around 60\%). Within regions, there was more diversity in the entry requirements in EMRO, SEARO and EURO (Table 1).
Direct-entry programmes for midwife education were reported by 63 countries (86\%). Six AFRO and two WPRO countries reported post-graduation entry (usually after a nursing qualification), and three countries (one each in AFRO, SEARO and PAHO) reported both direct and post-graduation entry programmes. The mean duration of training was longer for direct-entry programmes at 3.1 years than for post-graduation programmes at 1.8 years. For directentry programmes, WPRO had the shortest average length of training (2.2 years), and PAHO, EURO and AFRO the longest (4.0, 3.6 and 3.1 years, respectively). Only countries in the WPRO and AFRO regions reported post-nursing programmes, and these were similar in terms of mean duration of education, 1.5 and 1.8 years, respectively.

Overall, $81 \%$ of countries met the ICM minimum standard of 3 years for a direct-entry midwifery education programme or 18 months for a post-graduate training. For direct-entry programmes, just $30 \%$ of WPRO countries met this standard, compared with $90 \%$ in the AFRO region. In post-graduate programmes, there was little variation between regions.

Nearly all countries (92\%) reported having a standardised curriculum; however, only $52 \%$ had updated the curriculum in the preceding 3 years. Across regions, this ranged from $44 \%$ in the EMRO region to $83 \%$ in the PAHO region (Table 1).

Midwifery students need to provide care during labour and attend births under supervision [8]. The reported minimum number of supervised births to be completed before graduation ranged from 0 to 240 with a median of 33 (Table 1). There were 32 countries (44\%) who reported 30 or more births, 2 reported no minimum at all and 9 did not report this information. The PAHO region had the highest median (50 supervised births), although this ranged from 0 to 80 , and the EURO region the lowest median (5), because 3 out of 5 countries reported 5 although the responses ranged from 5 to 20 .

The most frequently reported challenges to the provision of high-quality midwifery education were the recruitment of teaching staff (56 of the 73 countries or $77 \%)$, limited opportunities for students to obtain practical skills $(n=56,77 \%)$ and the lack of or poor equipment available $(n=56,77 \%)$. Alignment of the curriculum with midwifery competencies was the least mentioned challenge $(n=18,25 \%)$. In the PAHO region, the unpreparedness of students from secondary education was also often reported. The WPRO region was particularly likely to report limited classroom space, as well as retaining staff capacity and the lack of opportunities for teachers to maintain and develop new skills (Table 2). 
Table 1 Characteristics of midwifery education and training, by region

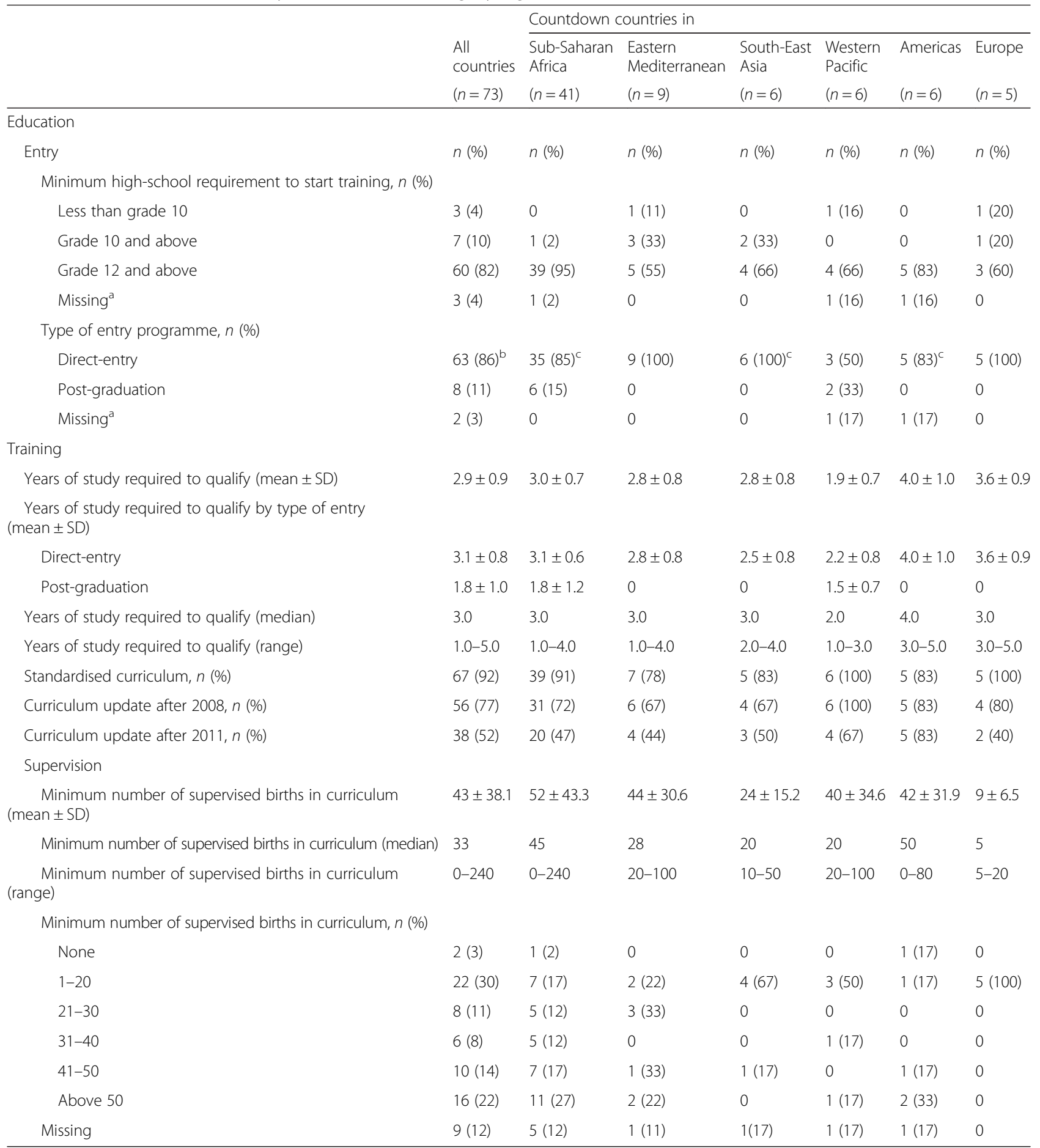

Note that the data only relate to the Countdown countries within each region and are not necessarily typical of the entire region

ancludes no reply and not applicable

${ }^{\mathrm{b}}$ Three countries reported both direct-entry and post-graduation programmes.

${ }^{\mathrm{c} O n e}$ country reported both direct-entry and post-graduation programmes

\section{Regulation}

Fewer than half of the countries (48\%) said they had legislation recognising midwifery as an autonomous regulated profession. This was most lacking in the
WPRO region, where none of the six countries reported such legislation, and in the SEARO region, only one did so. Despite this, $78 \%$ of the countries reported having an officially recognised definition of 
Table 2 Key challenges faced in the provision of quality education, by region

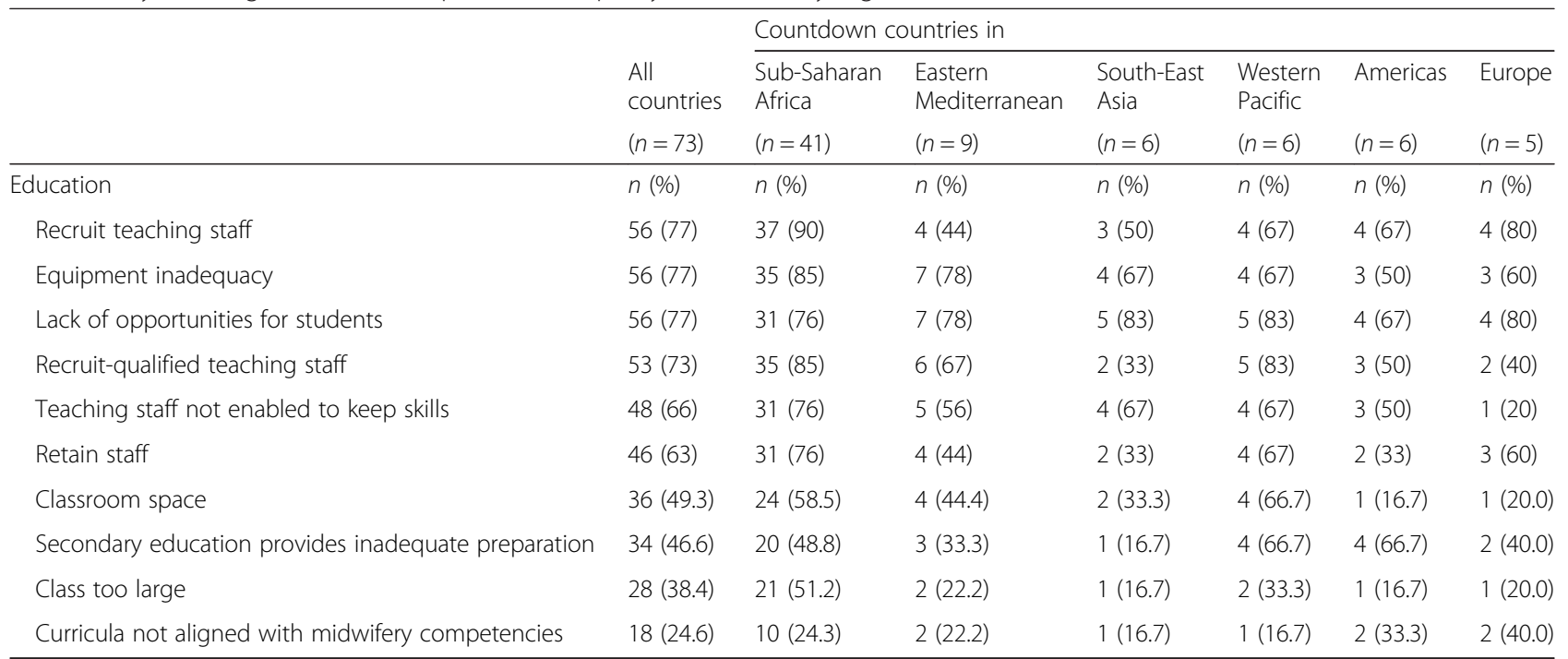

Note that the data only relate to the Countdown countries within each region and are not necessarily typical of the entire region

a professional midwife (ranging from 50\% in WPRO to $100 \%$ in EURO), and in $92 \%$ of the countries, it was reported that a government department or government-approved organisation assumed a regulatory role (Table 3). However, some countries qualified their response by noting that the regulatory body was not fully functional or needed support to fulfil its duties.

Respondents reported that regulatory organisations were responsible for the accreditation of education providers, setting standards for education and assuring the quality of education in 51 (70\%), 49 (67\%) and 39 (53\%) countries (Table 4). They also had a role in continuing professional development, assessing competency prior to registration and establishing the scope of midwifery practice. There was some regional variation. In the AFRO, WPRO, PAHO and EURO regions, regulatory responsibilities included accreditation of education providers as one of the main activities as well as setting standards for education. The EMRO and SEARO regions also listed continuing professional development as one of the main activities of the existing regulatory bodies. PAHO highlighted establishing the scope of midwifery practice, and both AFRO and WPRO included assessing competency prior to registration among the main roles.

\section{Professional associations}

Professional associations open to midwives were widely available in all regions although many were not exclusive to midwives. Three quarters (74\%) of countries had specific midwives association (Table 5); this ranged from $40 \%$ in the EURO to $85 \%$ in the AFRO region.

The roles of these associations were often related to continuing professional development and advising members on quality standards (93\%), as well as advising the government on the most recent national SRMNH policy (84\%) (Table 5). Similar results were observed across regions, except that associations in AFRO and PAHO were most likely to have a role as a negotiator on work or salary issues with governments.

Table 3 Characteristics of midwifery regulation, by region

\begin{tabular}{|c|c|c|c|c|c|c|c|}
\hline & \multirow{3}{*}{$\begin{array}{l}\text { All } \\
\text { countries } \\
(n=73)\end{array}$} & \multicolumn{6}{|c|}{ Countdown countries in } \\
\hline & & $\begin{array}{l}\text { Sub-Saharan } \\
\text { Africa }\end{array}$ & $\begin{array}{l}\text { Eastern } \\
\text { Mediterranean }\end{array}$ & $\begin{array}{l}\text { South-East } \\
\text { Asia }\end{array}$ & $\begin{array}{l}\text { Western } \\
\text { Pacific }\end{array}$ & Americas & Europe \\
\hline & & $(n=41)$ & $(n=9)$ & $(n=6)$ & $(n=6)$ & $(n=6)$ & $(n=5)$ \\
\hline Regulation & $n(\%)$ & $n(\%)$ & $n(\%)$ & $n(\%)$ & $n(\%)$ & $n(\%)$ & $n(\%)$ \\
\hline Legislation recognising midwifery as an autonomous profession & $38(52)$ & $18(44)$ & $4(44)$ & $5(83)$ & $6(100)$ & $2(33)$ & $3(60)$ \\
\hline A recognised definition of a professional midwife exists & $57(78)$ & $35(85)$ & $6(67)$ & $4(67)$ & $3(50)$ & $4(67)$ & $5(100)$ \\
\hline A government body regulates midwifery practice & $67(92)$ & $38(93)$ & $8(89)$ & $6(100)$ & $5(83)$ & $5(83)$ & $5(100)$ \\
\hline A licence is required to practise midwifery & $33(45)$ & $20(49)$ & $4(44)$ & $5(83)$ & 0 & $3(50)$ & $1(20)$ \\
\hline A live register of licensed midwives exists & $37(51)$ & $23(56)$ & $5(56)$ & $4(67)$ & $2(33)$ & $1(17)$ & $2(40)$ \\
\hline
\end{tabular}

Note that the data only relate to the Countdown countries within each region and are not necessarily typical of the entire region 
Table 4 Main activities undertaken by regulatory organisations, by region

\begin{tabular}{|c|c|c|c|c|c|c|c|}
\hline & \multirow[b]{2}{*}{$\begin{array}{l}\text { All } \\
\text { countries }\end{array}$} & \multicolumn{6}{|c|}{ Countdown countries in } \\
\hline & & $\begin{array}{l}\text { Sub-Saharan } \\
\text { Africa }\end{array}$ & $\begin{array}{l}\text { Eastern } \\
\text { Mediterranean }\end{array}$ & $\begin{array}{l}\text { South-East } \\
\text { Asia }\end{array}$ & $\begin{array}{l}\text { Western } \\
\text { Pacific }\end{array}$ & Americas & Europe \\
\hline & $(n=73)$ & $(n=41)$ & $(n=9)$ & $(n=6)$ & $(n=6)$ & $(n=6)$ & $(n=5)$ \\
\hline Regulation activities & $n(\%)$ & $n(\%)$ & $n(\%)$ & $n(\%)$ & $n(\%)$ & $n(\%)$ & $n(\%)$ \\
\hline Continuing professional development & $51(70)$ & $28(68)$ & $6(67)$ & $6(100)$ & $3(50)$ & $4(67)$ & $4(80)$ \\
\hline Accreditation of education providers & $51(70)$ & $29(71)$ & $5(56)$ & $3(50)$ & $4(67)$ & $5(83)$ & $5(100)$ \\
\hline Assessing competency prior to registration & $49(67)$ & $29(71)$ & $5(56)$ & $4(67)$ & $4(67)$ & $3(50)$ & $4(80)$ \\
\hline Setting standards for education & $49(67)$ & $29(71)$ & $6(67)$ & $4(67)$ & $1(17)$ & $4(67)$ & $5(100)$ \\
\hline Establishing the scope of midwifery practice & $44(60)$ & $28(68)$ & $5(56)$ & $2(33)$ & $3(50)$ & $5(83)$ & $1(20)$ \\
\hline Ensuring the quality of education & $39(53)$ & $25(61)$ & $4(44)$ & $3(50)$ & $2(33)$ & $2(33)$ & $3(60)$ \\
\hline
\end{tabular}

Note that the data only relate to the Countdown countries within each region and are not necessarily typical of the entire region

\section{Changes between SoWMy 2011 and SoWMy 2014}

Of the 54 countries which participated in both studies, 34 were from the AFRO region, 7 from EMRO, 5 from SEARO, 4 from WPRO and 2 each from PAHO and EURO. Since a different questionnaire was used in the two SoWMy reports, not all questions were directly comparable, so it was not possible to analyse time trends for all components of ERA. However, an overall improvement was observed between 2011 and 2014 for the questions common to both years (Table 6).

In education, there were many more direct-entry (only) programmes in 2014 than in 2011; in 2011, 19 countries had such programmes, and in 2014, 45 did, with increases observed in all regions. This was accompanied by an increase in the average duration of training towards international standards of at least 3 years for direct-entry programmes and 1.5 years for post-nursing programmes.
In 2014, 48 of the 54 countries reported that they had made progress in education since 2011, mostly in terms of the level of education, i.e. midwifery training was scaled up to international standards:

The length of the training programme for midwives was adjusted to last 3 years ... the training programmes ... were reviewed to align with ICMWHO skills.

Countries mentioned the creation or development of a diploma and/or Licence-Master-Doctorate (LMD) system and the review of the curricula to focus on emergency obstetric and neonatal care (EmONC) competencies, competencies/skills, and/or international guidelines. Improvements to structures to increase the availability and quality of education were mentioned, including supervision and development of internship systems:

Table 5 Characteristics of midwifery associations, by region

\begin{tabular}{|c|c|c|c|c|c|c|c|}
\hline & \multirow[b]{2}{*}{$\begin{array}{l}\text { All } \\
\text { countries } \\
(n=73)\end{array}$} & \multicolumn{6}{|c|}{ Countdown countries in } \\
\hline & & $\begin{array}{l}\text { Sub-Saharan } \\
\text { Africa } \\
(n=41)\end{array}$ & $\begin{array}{l}\text { Eastern } \\
\text { Mediterranean } \\
(n=9)\end{array}$ & $\begin{array}{l}\text { South-East } \\
\text { Asia } \\
(n=6)\end{array}$ & $\begin{array}{l}\text { Western } \\
\text { Pacific } \\
(n=6)\end{array}$ & $\begin{array}{l}\text { Americas } \\
(n=6)\end{array}$ & $\begin{array}{l}\text { Europe } \\
(n=5)\end{array}$ \\
\hline Association & $n(\%)$ & $n(\%)$ & $n(\%)$ & $n(\%)$ & $n(\%)$ & $n(\%)$ & $n(\%)$ \\
\hline Professional association exists that midwives can join & $72(97)$ & $41(100)$ & $9(100)$ & $6(100)$ & $6(100)$ & $6(100)$ & $4(80)$ \\
\hline Midwives-only association exists & $54(74)$ & $34(85)$ & $7(78)$ & $4(67)$ & $4(67)$ & $3(50)$ & $2(40)$ \\
\hline \multicolumn{8}{|l|}{ Associations' roles } \\
\hline Continuing professional development & $68(93)$ & $39(95)$ & $8(89)$ & $6(100)$ & $5(83)$ & $5(83)$ & $5(100)$ \\
\hline Advising members of quality standards & $68(93)$ & $40(98)$ & $7(78)$ & $6(100)$ & $5(83)$ & $5(83)$ & $5(100)$ \\
\hline $\begin{array}{l}\text { Advising the government on the most recent National MNH or } \\
\text { health policy document }\end{array}$ & $61(84)$ & $36(88)$ & $6(67)$ & $6(100)$ & $4(67)$ & $6(100)$ & $3(60)$ \\
\hline $\begin{array}{l}\text { Advising or representing members accused of misconduct or } \\
\text { incompetence }\end{array}$ & $50(67)$ & $32(78)$ & $4(44)$ & $5(83)$ & $3(50)$ & $3(50)$ & $3(60)$ \\
\hline Negotiating work or salary issues with the government & $46(63)$ & $31(76)$ & $2(22)$ & $4(67)$ & $2(33)$ & $5(83)$ & $2(40)$ \\
\hline
\end{tabular}


Table 6 Comparison of ERA elements between 2011 and 2014, by region

\begin{tabular}{|c|c|c|c|c|c|c|c|c|c|c|c|c|c|c|}
\hline \multirow[b]{3}{*}{ Education } & & & \multicolumn{12}{|c|}{ Countdown countries in } \\
\hline & \multicolumn{2}{|c|}{$\begin{array}{l}\text { All } \\
\text { countries } \\
(n=54)\end{array}$} & \multicolumn{2}{|c|}{$\begin{array}{l}\text { Sub-Saharan } \\
\text { Africa } \\
(n=34)\end{array}$} & \multicolumn{2}{|c|}{$\begin{array}{l}\text { Eastern } \\
\text { Mediterranean } \\
(n=7)\end{array}$} & \multicolumn{2}{|c|}{$\begin{array}{l}\text { South-East } \\
\text { Asia } \\
(n=5)\end{array}$} & \multicolumn{2}{|c|}{$\begin{array}{l}\text { Western } \\
\text { Pacific } \\
(n=4)\end{array}$} & \multicolumn{2}{|c|}{$\begin{array}{l}\text { Americas } \\
(n=2)\end{array}$} & \multicolumn{2}{|l|}{$\begin{array}{l}\text { Europe } \\
(n=2)\end{array}$} \\
\hline & 2011 & 2014 & 2011 & 2014 & 2011 & 2014 & 2011 & 2014 & 2011 & 2014 & 2011 & 2014 & 2011 & 2014 \\
\hline Type of entry & $n(\%)$ & $n(\%)$ & $n(\%)$ & $n(\%)$ & $n(\%)$ & $n(\%)$ & $n(\%)$ & $n(\%)$ & $n(\%)$ & $n(\%)$ & $n(\%)$ & $n(\%)$ & $n(\%)$ & $n(\%)$ \\
\hline Direct-entry only & $19(35)$ & $45(83)$ & $13(38)$ & $28(82)$ & $4(57)$ & $7(100)$ & $1(20)$ & $4(80)$ & $1(25)$ & $3(75)$ & 0 & $1(50)$ & 0 & $2(100)$ \\
\hline Combined only & $7(13)$ & NA & $4(12)$ & NA & 0 & NA & $2(40)$ & NA & 0 & NA & $1(50)$ & NA & 0 & NA \\
\hline Post-graduate only & $6(11)$ & $6(11)$ & $4(12)$ & $5(15)$ & 0 & 0 & 0 & 0 & 0 & $1(25)$ & $1(50)$ & 0 & $1(50)$ & 0 \\
\hline More than one type & $22(41)$ & $3(6)$ & $13(38)$ & $1(3)$ & $3(43)$ & 0 & $2(40)$ & $1(20)$ & $3(75)$ & 0 & 0 & $1(50)$ & $1(50)$ & 0 \\
\hline \multicolumn{15}{|l|}{ Length (in years) } \\
\hline \multicolumn{15}{|l|}{ Direct-entry (all) } \\
\hline$<3$ & $11(20)$ & $6(11)$ & $4(12)$ & $1(3)$ & $5(71)$ & $2(29)$ & $2(40)$ & $1(20)$ & 0 & $2(50)$ & 0 & 0 & 0 & 0 \\
\hline$\geq 3$ & $23(43)$ & $38(70)$ & $20(59)$ & $26(77)$ & $1(14)$ & $5(71)$ & 0 & $3(60)$ & $1(25)$ & $1(25)$ & 0 & $1(50)$ & $1(50)$ & $2(100)$ \\
\hline Missing & $3(6)$ & $10(19)$ & $1(3)$ & $7(21)$ & $1(14)$ & 0 & 0 & $1(20)$ & $1(25)$ & $1(25)$ & 0 & $1(50)$ & 0 & 0 \\
\hline \multicolumn{15}{|l|}{ Post-graduate (all) } \\
\hline$<1.5$ & $10(19)$ & $4(7)$ & $5(15)$ & $3(9)$ & $3(43)$ & 0 & 0 & 0 & $2(50)$ & $1(25)$ & 0 & 0 & 0 & 0 \\
\hline$\geq 1.5$ & $10(19)$ & $2(4)$ & $7(20)$ & $2(6)$ & 0 & 0 & $1(20)$ & 0 & $1(25)$ & 0 & 0 & 0 & $1(50)$ & 0 \\
\hline Missing & 0 & 0 & 0 & 0 & $4(57)$ & 0 & $4(80)$ & 0 & $1(25)$ & 0 & $2(100)$ & 0 & $1(50)$ & 0 \\
\hline \multicolumn{15}{|l|}{ Regulation, $n(\%)$} \\
\hline $\begin{array}{l}\text { Legislation exists } \\
\text { recognising midwifery } \\
\text { as an autonomous } \\
\text { profession }\end{array}$ & $19(35)$ & $24(44)$ & $15(44)$ & $20(59)$ & $1(14)$ & $3(43)$ & $3(60)$ & $1(20)$ & 0 & 0 & 0 & 0 & 0 & 0 \\
\hline $\begin{array}{l}\text { A recognised definition } \\
\text { of a professional } \\
\text { midwife exists }\end{array}$ & $39(72)$ & $44(82)$ & $28(82)$ & $31(91)$ & $2(15)$ & $4(57)$ & $4(80)$ & $3(60)$ & $3(75)$ & $3(75)$ & 0 & $1(50)$ & $2(100)$ & $2(100)$ \\
\hline $\begin{array}{l}\text { A government body } \\
\text { regulates } \\
\text { midwifery practice }\end{array}$ & $39(72)$ & $51(94)$ & $27(79)$ & $32(94)$ & $4(57)$ & $6(86)$ & $3(60)$ & $5(100)$ & $2(50)$ & $4(100)$ & $1(50)$ & $2(100)$ & $2(100)$ & $2(100)$ \\
\hline \multicolumn{15}{|l|}{ Association, $n(\%)$} \\
\hline $\begin{array}{l}\text { Professional association } \\
\text { exists that } \\
\text { midwives can join }\end{array}$ & $51(94)$ & $54(100)$ & $34(100)$ & $34(100)$ & $5(71)$ & $7(100)$ & $5(100)$ & $5(100)$ & $3(75)$ & $4(100)$ & $2(100)$ & $2(100)$ & $2(100)$ & $2(100)$ \\
\hline $\begin{array}{l}\text { Midwives-only } \\
\text { association exists }\end{array}$ & $31(57)$ & $45(83)$ & $22(65)$ & $30(88)$ & $3(43)$ & $7(100)$ & $3(60)$ & $4(80)$ & $2(50)$ & $3(75)$ & 0 & $1(50)$ & $1(50)$ & 0 \\
\hline
\end{tabular}

Note that the data only relate to the Countdown countries within each region and are not necessarily typical of the entire region

The curriculum has been designed; an obstetric laboratory is under construction along with a training project for teachers and internship supervisors.

Regulation also showed improvements overall. Between 2011 and 2014, seven countries introduced legislation recognising midwifery as an autonomous profession (five in AFRO and two in EMRO). On the other hand, in WPRO, PAHO and EURO no such progress was made, and 2 SEARO countries appeared to have retracted the legislation that existed in 2011 (in fact, one of these reported not having legislation in 2014 because it was at that moment in the process of evolving from a decree/act to higher legislation (Law/Act) on health professions, in which midwifery is recognised as an independent profession). Likewise, six countries (three in AFRO, two in EMRO and one in PAHO) said that a recognised definition of a professional midwife had been introduced since 2011. The most striking improvement related to regulation by a governmentapproved body was that between 2011 and 2014, 12 countries across 5 regions changed their response to this question from 'no' to 'yes' (5 in AFRO, 2 in EMRO, 2 in SEARO, 2 in WPRO and 1 in PAHO).

When asked to specify improvements in regulation since 2011 , only 30 out of the 54 countries gave a response. In most cases, this involved the creation of a national board or council or the review or development of midwives' scope of practice, for example: 
We developed a scope of practice for midwifery, reviewed the midwifery handbook to include ICM competencies and global innovations.

Some countries also mentioned the development of a registration system or the creation of a code of conduct or an official definition of the profession:

The midwives code of conduct has been available since 2013 in its revised version, taking into account the current realities of the profession and technological advancements, including the list of equipments and materials essential for $\mathrm{MNH}$ and the list of medicine that can be prescribed by midwives with essential ICM skills.

With respect to professional associations, great improvements were seen. In 2011, 51 of the 54 countries had an association that midwives could join, and by 2014, all the 54 did. Perhaps more importantly, the number of countries with an association specifically for midwives increased from 31 to 45 , and only the EURO region showed no progress.

More than two thirds of the 54 countries $(n=37)$ reported improvements in association, e.g. the creation of associations independent of other professions and the benefits of becoming an ICM member. Partnerships, participation and involvement in discussions regarding MNH care were also mentioned, particularly in policy- and decision-making:

The midwives association is often solicited to participate in different activities organised by the Health Ministry, notably to plan the sector.

Some countries also reported improvements in terms of leadership capacity and decentralisation processes.

\section{Limitations}

This study has some limitations, which need to be taken into account when interpreting the findings. Although countries from all the WHO regions were involved in the study, it only included those lowand middle-income countries (LMICs) that are part of the Countdown to 2015 initiative. These countries are not necessarily representative of their regions, and findings may not be generalisable to other countries in the region. The data were provided by UNFPA and WHO focal points in each country, after consultation with relevant stakeholders. The results were validated within the countries, but no external validation or triangulation of the responses was carried out, so some data quality issues may remain in countries with weak health management information systems. In addition, the education information provided tended not to include private sector schools, where these exist. Neither did it include much information about practical elements of midwifery education, offering only an overview of the issues affecting classroom-based education.

\section{Discussion}

This study explored the components of ERA of midwives in 73 LMICs and compared them across regions. Overall, the study showed that many LMICs are working towards international standards established for ERA, which support and enable the development of midwifery as a profession. However, not all components are being implemented equally and some variability persists among these LMICs, both between and within regions.

Overall, all the three ERA pillars have evolved and improved in these LMICs since 2011. Education is considered the key for quality of care and better health outcomes, as is the process of developing and maintaining competencies [14]; therefore, a larger investment may have occurred in this area. In 2014, the aspects that showed greatest progress towards international standards for education were the entry requirements for enrolment into a midwifery course, duration of training and use of a standardised curriculum $[8,9]$. In all countries, and particularly those which do not apply international standards on entry level and duration of training (Botswana, Kenya, Myanmar, Papua New Guinea, Sierra Leone, Solomon Islands, South Africa, Viet Nam, Zambia and Zimbabwe), it would be interesting to conduct rigorous evaluations of education quality to determine whether increased duration of education programmes translated to improved quality of graduates. Other issues should be considered, in particular the organisation of the training. The West Africa Health Organisation (WAHO) is working on harmonising curricula with a common year of training for nursing and midwifery: it would be of interest to see if the ICM competencies are fully implemented in such a configuration. In some countries it may be a consequence of the choice to include the training of midwives within the LMD system, in an attempt to align their training structure with that of other medical/ clinical professions.

Another issue is related to the proportion and quality of practical compared to theoretical education. Apart from the need for investment in the development of skills and competencies of education facilitators, students require adequately resourced 
supervised clinical practice $[2,19]$. Many LMICs from different regions mentioned this as one of the main barriers to education. Quality and also duration of practical training are key aspects: those have to be taken into account when establishing common training with other students or developing new curricula.

Robust evaluation of the quality of theoretical and practical midwifery education is necessary to validate country efforts and to improve the quality of education. WHO and UNFPA are currently supporting such evaluations in a number of countries, but countries' own evaluations of midwifery education and schools' accreditation systems would bring about quality improvements, particularly in LMICs such as those involved in this study. The number of births attended by students during their education can be a proxy for quality $[2,20]$, and in this study, inconsistencies were observed between countries and regions on this measure. The source of such a disparity could be the absence of a reference or benchmark for the minimum number of supervised births, as evaluation is a subjective process which relies mostly on supervisor observation and taking a competency-based approach rather than one based on minimum numbers [8].

Regulation is critical for the protection of service users and of midwives themselves. Midwives should not only know the boundaries of their authorised practice but also maintain their practice within these boundaries. Some progress was observed since 2011 in the availability of a regulatory body, which often was the government itself, and the existence of a recognised definition of a professional midwife. Further research on these countries could provide insight whether there was improvement in quality of and access to SRMNH care in comparison to those who reported no change to legislative or regulatory mechanisms.

Our findings showed an increase in the number of LMICs with professional associations that are open to midwives, particularly associations specifically for midwives. Associations are more and more recognised as an important mechanism for strengthening the profession [2, 14]. Evidence shows the importance of an enabling work environment [5], and professional associations can contribute to this by optimising the value of midwives and providing a link between policy and implementation [21].

Across this group of LMICs, ERA has not evolved uniformly even where overall progress was strong. Our results show a high level of uniformity in the AFRO and PAHO regions. Since 2011, the WPRO and SEARO regions showed less consistent progress, while AFRO and EMRO showed more significant improvements towards international standards. This discrepancy could be due to countries having departed from very different start points. Alternatively, it may be an indication of the impact of SoWMy 2011 as an advocacy tool for midwifery and the use of a more standardised and coordinated approach to ERA, particularly in the AFRO and EMRO regions.

The 2014 findings showed there was still some variability within regions in relation to education. Education standardisation, which should guide countries to highquality and competency levels of the health workforce, could be undermined by the implementation of shortterm strategies (or short cuts) in terms of planning due to the pressure of severe health workforce shortfalls and/or high unmet need for SRMNH care [22].

The observed improvements in the AFRO region are particularly interesting as it is the region where relatively poor maternal and newborn health outcomes are observed. Our findings may be reflecting recent investments made in midwifery and SRMNH through development aid within the framework of Millennium Development Goals (MDGs) 4 and 5 and in the overall strengthening of health systems/ workforce [1,23]. The progress observed since 2011 and towards international standards could therefore lead to future health gains. On the other hand, the slow progress observed in health indicators in the region could also be related to the existence and persistence of key challenges for quality education $[14,24]$ as well as wider issues which impact on health outcomes.

In 2014, LMICs in the PAHO region reported the highest proportion of countries with legislation, especially in comparison to WPRO, where legislation was non-existent in all the countries included in this study. This might go some way towards explaining why education standards showed more variability and less development when compared against international standards and other regions. This may result from the growing number of private schools and of donor scholarships in the WPRO region, in particular in the Islands [25] which could be improved by a clear definition, legislative support and accreditation systems that would enable standardisation of programmes [25].

Despite the promising improvements in regulation since 2011, this is still the pillar where most variability lies. Between 2011 and 2014, the existence of legislation as well as the recognised definition supporting the midwifery professionals seemed to be left behind in LMICs in at least three regions. According to ICM's Global Standards for Midwifery Regulation, legislation identifies who is a midwife and who is not and describes the scope of midwifery practice [10]. Regulation is built upon this 
legislation, establishing the set of criteria and processes that supports midwives to work autonomously within their full scope of practice $[10,14]$. If there is no legislation to support regulation activities, the recognition and scope of midwife practice can be limited and inefficient, even if the government is the main regulator [26]. There is a lack of clarity in many countries around the role and scope of practice of the midwife, and this flows into uncertainties in education and practice. Every country needs to advocate for such clarity in legislation. Further research must also be conducted into the impact of clarity around the role and scope of practice on improvements in maternal and newborn health outcomes.

In the post-2015 agenda, the midwifery workforce will only be able to respond fully to SRMNH needs and new challenges if ERA are strong. This study pointed to some lines of action which could help to overcome challenges and improve ERA across regions, including the following: (1) simultaneous and holistic improvements to ERA as strengthening one in isolation is unlikely to address overall quality; (2) assuring the development or strengthening of legislation that recognises midwifery and could support education and association; (3) integration of ERA elements in national mechanisms of planning and strategy such as national SRMNH or health workforce plans; (4) making the best use of existing structures (e.g. associations and councils) which could advocate for ERA, increasing the involvement of stakeholders and providing evidence; regional observatories could coordinate regional actions and facilitate cooperation between countries to increase standardisation; (5) implementation of regular monitoring and evaluation activities and accountability mechanisms, which could provide timely and valuable information about progress and sustainability of investing in ERA for midwifery workforce development; and (6) conducting further research on ERA to improve and increase adaptability of ICM standards, including a better understanding of the interdependency between elements.

\section{Conclusions}

This study showed that despite positive effects from recent investments in the midwifery workforce, among LMICs inter-regional disparities exist in education, regulation and association (ERA), the three fundamental pillars that support and enable professional development. Of these three pillars, education showed the most systematic improvement, although not uniformly across regions. The reinforcement of regulation through the development of legislation for midwifery, a recognised definition, as well as the strengthening of midwives' associations would benefit the development of other ERA elements and the profession generally. Further work is needed to develop ERA in all countries to international standards and to accompany this investment with substantial progress on midwifery workforce management, so that the full potential of midwifery care can be realised.

\section{Appendix}

Table $\mathbf{7}$ List of participating countries, by region

\begin{tabular}{|c|c|c|c|c|c|}
\hline $\operatorname{AFRO}(n=41)$ & SEARO $(n=6)$ & WPRO $(n=6)$ & PAHO $(n=6)$ & $\operatorname{EMRO}(n=9)$ & $\overline{\text { EURO }(n=5)}$ \\
\hline Angola & Bangladesh $^{a}$ & Cambodia $^{a}$ & Bolivia $^{a}$ & Afghanistan $^{\text {a }}$ & Azerbaijan \\
\hline Benin $^{a}$ & India ${ }^{a}$ & China & Brazil & Djibouti $^{a}$ & Kyrgyzstan \\
\hline Botswana ${ }^{a}$ & Indonesia ${ }^{a}$ & Lao PDR ${ }^{a}$ & Guatemala & Egypt & Tajikistan $^{a}$ \\
\hline Burkina Faso ${ }^{a}$ & Korea DPR & Papua New Guinea ${ }^{a}$ & Haiti $^{a}$ & Iraq & Turkmenistan \\
\hline Burundi ${ }^{a}$ & Myanmar ${ }^{a}$ & Solomon Islands & Mexico & Morocco $^{\mathrm{a}}$ & Uzbekistan $^{\mathrm{a}}$ \\
\hline Cameroon $^{a}$ & $\mathrm{Nepa}^{a}$ & Viet Nam ${ }^{a}$ & Peru & Pakistan $^{\mathrm{a}}$ & \\
\hline Central African Republic $^{a}$ & & & & Somalia $^{a}$ & \\
\hline Chad $^{\mathrm{a}}$ & & & & Sudan ${ }^{\mathrm{a}}$ & \\
\hline Comoros $^{\mathrm{a}}$ & & & & Yemen $^{\mathrm{a}}$ & \\
\hline \multicolumn{6}{|l|}{ Congo } \\
\hline \multicolumn{6}{|l|}{ Congo DR ${ }^{a}$} \\
\hline \multicolumn{6}{|l|}{ Côte d'Ivoire ${ }^{a}$} \\
\hline \multicolumn{6}{|l|}{ Eritrea } \\
\hline \multicolumn{6}{|l|}{ Ethiopia $^{a}$} \\
\hline Gabon $^{a}$ & & & & & \\
\hline
\end{tabular}


Table 7 List of participating countries, by region (Continued)

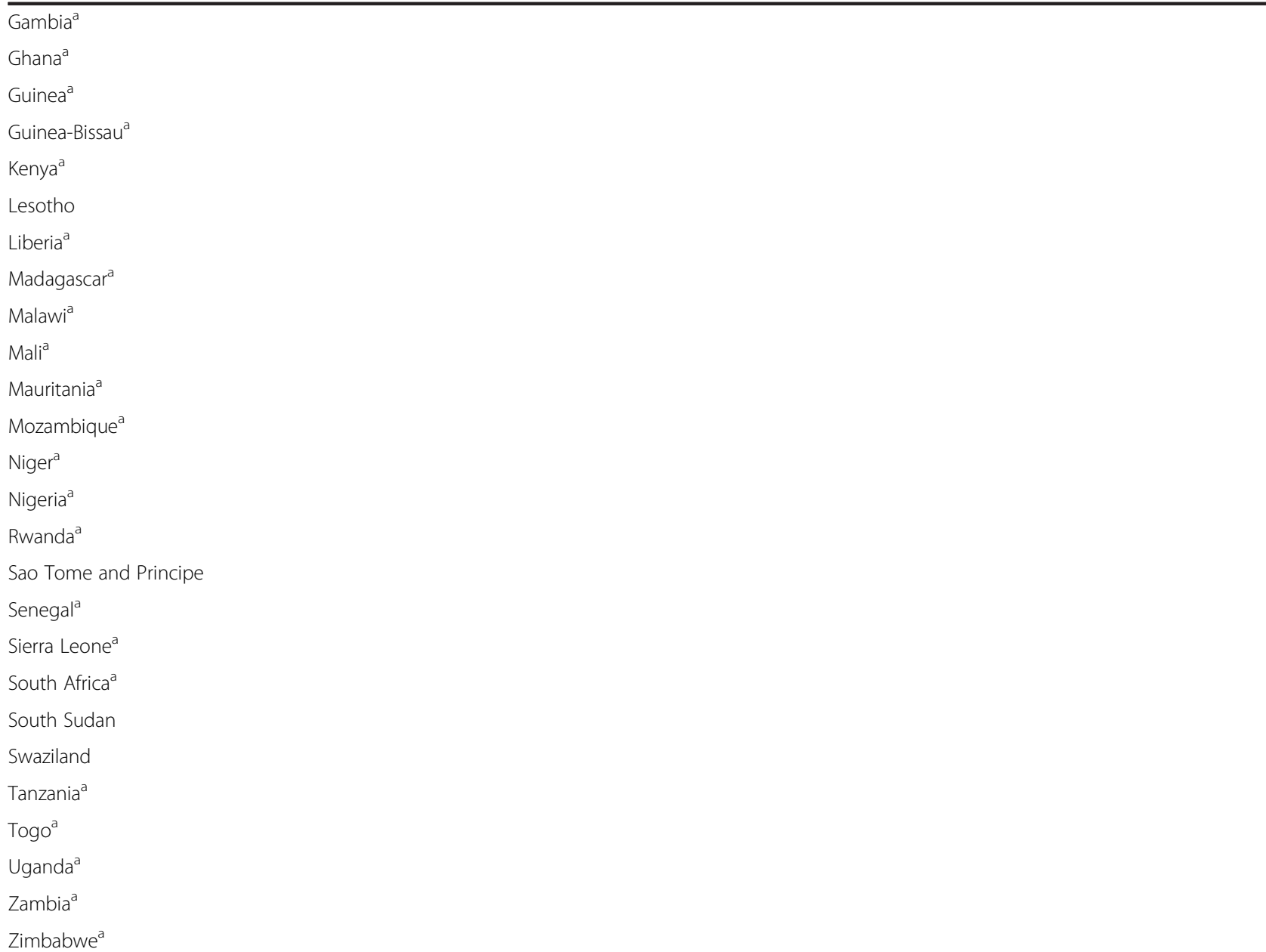

${ }^{a}$ Also participated in SoWMy 2011

\section{Abbreviations}

AFRO, Africa Regional Office (WHO), covering sub-Saharan Africa; EmONC, emergency obstetric and neonatal care; EMRO, Eastern Mediterranean Regional Office (WHO); ERA, education, regulation, association; EURO, Europe Regional Office (WHO); ICM, International Confederation of Midwives; LMD, Licence-Master-Doctorate; LMICs, low- and middle-income countries; MDG, Millennium Development Goal; PAHO, Pan American Health Organization (WHO Americas Regional Office); SEARO, South-East Asia Regional Office (WHO); SoWMy, State of the World's Midwifery; SRMNH, sexual, reproductive, maternal and newborn health; UNAIDS, Joint United Nations Programme on HIV/AIDS; UNFPA, United Nations Population Fund; UNICEF, United Nations Children's Fund; WAHO, West African Health Organisation; WHO, World Health Organization; WPRO, Western Pacific Regional Office (WHO)

\section{Acknowledgements}

We thank everyone who was involved in the preparation of the SoWMy 2011 and 2014 reports, in particular the UNFPA and WHO country offices as well as the national Midwives Associations. We also thank Dr Paul Van Look for reviewing an early draft of this paper and providing helpful suggestions. This study was possible through a financial grant provided by the Bill \& Melinda Gates Foundation.

\section{Authors' contributions}

PHB and $\mathrm{CH}$ conceptualised the study. SCL conducted the analysis with advice from $\mathrm{CH}, \mathrm{PHB}$ and $\mathrm{AN}$. SCL and $\mathrm{AN}$ prepared an initial draft of the paper, to which all authors contributed important revisions. All authors read and approved the final manuscript.

\section{Competing interests}

The authors declare that they have no competing interests.

\section{Author details}

${ }^{1}$ ICS Integrare, calle Balmes, 30,3-1, 08007 Barcelona, Spain. ${ }^{2}$ Women's Health and Development, Geneva, Switzerland. ${ }^{3}$ UNFPA, 11-13 Chemin des Anémones, 1219 Chatelaine, Switzerland. ${ }^{4}$ ICM, Laan van Meerdervoort 70, 2517 AN The Hague, The Netherlands. ${ }^{5}$ University of Technology Sydney, 15 Broadway, Ultimo, NSW 2007, Australia.

Received: 30 October 2015 Accepted: 31 May 2016

Published online: 08 June 2016

\section{References}

1. Requejo JH, Bryce J, Victora C, and the Countdown writing team. Fulfilling the health agenda for women and children. The 2014 report. UNICEF and WHO; 2014

2. UNFPA, WHO, ICM. The State of the World's Midwifery 2014: a universal pathway. A woman's right to health. New York: United Nations Population Fund; 2014.

3. Ten Hoope-Bender $P$, de Bernis L, Campbell J, Downe S, Fauveau V, Fogstad $H$, et al. Improvement of maternal and newborn health through midwifery. 
Lancet [Internet]. 2014;384:1226-35. Available from: http://linkinghub. elsevier.com/retrieve/pii/S0140673614609302.

4. Horton R. Offline: failing women and failing them badly. Lancet [Internet]. 2013;382:1082. Elsevier Ltd. Available from: http://linkinghub.elsevier.com/ retrieve/pii/S0140673613619716.

5. Renfrew MJ, McFadden A, Bastos MH, Campbell J, Channon AA, Cheung NF, et al. Midwifery and quality care: findings from a new evidence-informed framework for maternal and newborn care. Lancet [Internet]. 2014;384 1129-45. Available from: http://www.ncbi.nlm.nih.gov/pubmed/24965816.

6. Homer C, Friberg IK, Bastos Dias MA, ten Hoope-Bender P, Sandall J, Speciale AM, et al. The projected impact of scaling up midwifery. Lancet [Internet]. 2014;384:1146-57. Available from: http://www.thelancet.com/ journals/lancet/article/PIIS0140-6736(14)60790-X/abstract.

7. Van Lerberghe W, Matthews Z, Achadi E, Ancona C, Campbell J, Channon A, et al. Country experience with strengthening of health systems and deployment of midwives in countries with high maternal mortality. Lancet [Internet]. 2014;384:1215-25. Available from: http://www.thelancet.com/ journals/lancet/article/PIIS0140-6736(14)60919-3/fulltext.

8. International Confederation of Midwives. Global standards for midwifery education (2010): amended 2013 [Internet]. The Hague, Netherlands; 2013 [cited 2015 Jun 9]. p. 1-9. Available from: http://internationalmidwives.org/ assets/uploads/documents/CoreDocuments/ ICM\%20Standards\%20Guidelines_ammended2013.pdf Guidelines for ED standards 2011 - amended web edition June 2013.pdf

9. International Confederation of Midwives. Essential competencies for basic midwifery practice 2010. Revised 2013. [Internet]. The Hague: ICM; 2013. Available from: http://www.internationalmidwives.org/assets/uploads/ documents/CoreDocuments/ICM\%20Essential\%20Competencies\%20 for\%20Basic\%20Midwifery\%20Practice\%202010,\%20revised\%202013.pdf Essential Competencies for Basic Midwifery Practice 2010, revised 2013.pdf.

10. International Confederation of Midwives. Global standards for midwifery regulation. Regulation [Internet]. 2011. p. 1-24. Available from: http://www. internationalmidwives.org/assets/uploads/documents/ Global\%20Standards\%20Comptencies\%20Tools/English/ GLOBAL\%20STANDARDS\%20FOR\%20MIDWIFERY\%20REGULATION\%20ENG.pdf.

11. International Confederation of Midwives. Member association capacity assessment tool (MACAT) [Internet]. 2014 [cited 2015 Jun 10]. Available from: http://www.internationalmidwives.org/what-we-do/associationcoredocuments/macat.html.

12. International Confederation of Midwives. Member association capacity assessment tool (MACAT) guidelines. International Confederation of Midwives; 2011. Available from: http://www.internationalmidwives.org/ assets/uploads/documents/Global\%20Standards\%20Comptencies\%20Tools/ English/MACAT\%20Guidelines\%20ENG.pdf.

13. International Confederation of Midwives. Education, regulation and association [Internet]. 2014. Available from: http://www. internationalmidwives.org/what-we-do/education-regulation-association/.

14. UNFPA. State of the World's Midwifery 2011: delivering health, saving lives. New York: United Nations Population Fund; 2011.

15. Partnership for Maternal Newborn and Child Health. Countdown to 2015: tracking progress in maternal, newborn and child survival [lnternet]. 2014 [cited 2015 Jan 5]. Available from: http://www.countdown2015mnch.org/ about-countdown

16. Tanahashi T. Health service coverage and its evaluation. Bull World Health Organ. 1978:56:295-303.

17. Campbell J, Buchan J, Cometto G, David B, Dussault G, Fogstad H, et al. Human resources for health and universal health coverage: fostering equity and effective coverage. Bull World Heal Organ. 2013;91:853-63.

18. World Health Organization. $\mathrm{H} 4+$ high burden country initiative ( $\mathrm{HBCl})$ [Internet]. 2016 [cited 2016 Feb 17]. Available from: http://www.who.int/ workforcealliance/countries/hbci/en/index.html

19. West F, Homer C, Dawson A. Building midwifery educator capacity in teaching in low and lower-middle income countries. A review of the literature. Midwifery [Internet]. Elsevier; 2015. p. 1-12. Available from: http:// linkinghub.elsevier.com/retrieve/pii/S026661381500193X.

20. WHO Regional Office for the Eastern Mediterranean. A guide to nursing and midwifery education standards. 2015.

21. International Confederation of Midwives. Twinning as a tool for strengthening midwives associations: operational manual. The Hague: International Confederation of Midwives; 2014
22. Campbell J, Sochas L, Cometto G, Matthews Z. Evidence for action on improving the maternal and newborn health workforce: the basis for quality care. Int J Gynecol Obstet [Internet]. 2016;132:126-9. Elsevier. Available from: http://dx.doi.org/10.1016/.ijgo.2015.11.003.

23. Powell-Jackson T, Borghi J, Mueller DH, Patouillard E, Mills A. Countdown to 2015: tracking donor assistance to maternal, newborn, and child health. Lancet [Internet]. 2006;368:1077-87. Available from: http://www.thelancet. com/pdfs/journals/lancet/PIIS0140-6736(06)69338-0.pdf.

24. UNFPA. UNFPA maternal mortality update 2006. Expectation and delivery: investing in midwives and others with midwifery skills. 2006

25. McKimm J, Newton PM, Da Silva A, Campbell J, Condon R, Kafoa B, et al. Accreditation of healthcare professionals' education in Pacific Island countries: evidence and options. Hub Policy Briefs: UNSW HRH Knowl; 2013.

26. McCarthy CF, Voss J, Salmon ME, Gross JM, Kelley MA, Riley PL. Nursing and midwifery regulatory reform in east, central, and southern Africa: a survey of key stakeholders. Hum Resour Health [Internet]. 2013;11:29. Available from: http://human-resources-health.biomedcentral.com/articles/10.1186/14784491-11-29.

\section{Submit your next manuscript to BioMed Central and we will help you at every step:}

- We accept pre-submission inquiries

- Our selector tool helps you to find the most relevant journal

- We provide round the clock customer support

- Convenient online submission

- Thorough peer review

- Inclusion in PubMed and all major indexing services

- Maximum visibility for your research

Submit your manuscript at www.biomedcentral.com/submit
C Biomed Central 